\title{
TEORIAS DO PLANEJAMENTO E SOBRE A PRODUÇÃO SOCIOESPACIAL URBANA NO BRASIL Referências paulistanas
}

\section{THEORIES OF PLANNING AND ABOUT URBAN SOCIO-SPATIAL PRODUCTION IN BRAZIL São Paulo references}

\author{
A. Sergio Abrahão \\ UNIP, Universidade Paulista, São Paulo, Brasil \\ sergioabrahao15@gmail.com
}

\author{
B. Silvana Zioni \\ UFABC, Universidade Federal do ABC, São Paulo, Brasil \\ silvana.zioni@gmail.com
}

\begin{abstract}
RESUMO
O presente trabalho é fruto de reflexões iniciais no bojo de uma investigação em andamento que busca estabelecer o contexto e os principais debates e trabalhos realizados por intelectuais nacionais e internacionais, que contribuíram para pavimentar o caminho em direção à construção de uma teoria da urbanização e das questões urbanas no Brasil e, em especial, na cidade de São Paulo em seu processo de metropolização, entre os anos 1960 e 1970. No âmbito de tal investigação destaca-se, através da produção do arquiteto Flávio Villaça, os traços e liames da imbricada relação que se estabeleceu, a partir daquele período, especificamente entre as teorias do planejamento e a produção socioespacial urbana, destacando algumas entre suas mais importantes produções bibliográficas.
\end{abstract}

Palavras-chave: estudos urbanos, teorias de planejamento urbano, urbanismo, São Paulo.

Linha de Investigação: 1: Cidade e Projeto - História Urbana e História do Urbanismo.

\section{ABSTRACT}

The present work is the result of initial reflections as part of an ongoing investigation that seeks to establish the context and the main debates and works carried out by national and international intellectuals, which contributed to pave the way towards the construction of a theory of urbanization and urban issues in Brazil and, in particular, in the city of São Paulo in its process of metropolization, between the 1960s and 1970s. Within the scope of this investigation, through the production of the architect Flávio Villaça, the traces and 


\section{SÃO PAULO15 17 LISBOA $25 \sim 26$ JUN 2020}

links of the interlocking relationship that was established, from that period, specifically between the theories of planning and urban socio-spatial production, highlighting some of its most important bibliographic productions.

Keywords: urban studies, theories of urban planning, urbanism, São Paulo.

Research line: 1: City and Project - Urban History and History of Urbanism.

\section{Introdução}

Este artigo apresenta-se como uma reflexão preliminar, fruto de uma pesquisa ainda em andamento, que procura estabelecer alguns referenciais sobre a construção de uma teoria da urbanização e das questões urbanas no Brasil. Partindo da compreensão do contexto e dos principais debates ocorridos, mas relendo também os trabalhos realizados, seja por intelectuais nacionais ou internacionais, busca-se avaliar como esses contribuíram para pavimentar o caminho em direção a essa produção, em especial na cidade de São Paulo em seu momento de metropolização, entre os anos 1960 e 1970.

O foco principal deste artigo é feito sobre a trajetória do arquiteto e urbanista Flávio Jose Magalhães Villaça, apontando fatores determinantes na formação e na sua produção como pesquisador do espaço urbano. Importante destacar inicialmente que suas atividades estão vinculadas tanto às suas práticas, enquanto profissional autônomo, ou funcionário público em diversos órgãos municipais ou estaduais de planejamento, quanto em sua trajetória acadêmica na Faculdade de Arquitetura e Urbanismo da Universidade São Paulo, iniciada em 1974. Para tanto, o artigo resgata por um lado, as discussões que tiveram lugar em uma das sessões temáticas, do último ENANPARQ, realizado em 2018, na cidade de Salvador/BA., quando se apresentou uma sistematização critica das reflexões de Villaça em torno da renda da terra, da estruturação socio-espacial das metrópoles brasileiras e da produção dos centros dessas metrópoles e, por outro, retoma também, os primeiros resultados da investigação sobre os aportes teóricos seminais, na formação de seu pensamento urbanístico.

O presente trabalho é resultado desse desafio de pesquisa. Estruturado em três seções além dessa introdução, busca-se estabelecer na primeira delas alguns marcos da construção da trajetória de Flávio Villaça como planejador e pesquisador. Em seguida, é traçado um quadro de referências bastante abrangente sobre a emergência, em São Paulo nos anos 1970, dos principais debates e trabalhos realizados por intelectuais marxistas em torno da construção de uma teoria da urbanização na periferia do capitalismo e das questões urbanas. É onde se pode identificar-as principais influências e os principais interlocutores de Villaça, no período de sua adesão ao materialismo histórico na década de 1970, então considerado período de crítica radical por Manuel Castells. Finalmente, apenas antecipando algumas conclusões, apresenta-se uma breve reflexão sobre a importância e abrangência dos trabalhos de Flávio Villaça, desde sua adesão ao materialismo histórico, e do diálogo estabelecido com outros pesquisadores das várias áreas do conhecimento, que como ele estavam preocupados em entender o processo de estruturação intra-urbano das metrópoles brasileiras.

\section{A construção de uma trajetória}

Como ponto de partida do percurso de Flávio Villaça pelas teorias do planejamento e da produção socioespacial urbana, adota-se o período de seu doutoramento, realizado entre 1974 a 1979 , no Departamento de Geografia, da Faculdade de Filosofia Letras e Ciências Humanas da USP (FFLCH - USP), por ser o período que marca uma inflexão decisiva em sua trajetória intelectual, quando, ao questionar, por 


\section{SÃO PAULO15 $\sim 17 \cdot$ LISBOA $25 \sim 26$ JUN 2020

entender insatisfatórias, as explicações sobre o processo de estruturação do espaço urbano, presentes nas teorias positivistas que, então, predominavam na economia, na geografia e na sociologia urbanas, passa a adotar o materialismo histórico e dialético como chave para entender e explicar o processo, extremamente complexo, de estruturação urbana das metrópoles brasileiras.

De fato, do período de sua graduação, em meados dos anos 50 , aos nossos dias foram décadas de intensa dedicação à prática profissional, ao ensino e à pesquisa, conjugando sempre sua atuação profissional, em instituições públicas e privadas, com as atividades acadêmicas que desenvolveu tanto como professor da graduação e pós-graduação, quanto como pesquisador incansável na área do planejamento e da produção socioespacial urbana, o que marcaria fortemente a trajetória e a qualidade de sua produção intelectual.

O mestrado, realizado entre 1956 e 1958 - logo após se graduar na Faculdade de Arquitetura e Urbanismo da Universidade de São Paulo (FAU USP) - se deu junto ao programa de 'Master of City Planning' do Georgia Institute of Technology (Atlanta, EUA), culminando com a apresentação da dissertação 'The Experience of Planning And Building Of New Towns And Its Applications To Brazil's New Capital City': uma reflexão sobre as teorias de Cidades Novas, realizada simultaneamente ao projeto de construção de Brasília.

Quando retorna ao país após a conclusão do mestrado, retoma seu cargo de arquiteto no Departamento de Urbanismo da Prefeitura Municipal de São Paulo, quando, então se propõe a estudar a pesquisa que havia sido realizada, pela Sociedade de Analises Gráficas e Mecanográficas Aplicadas aos Complexos SociaisSAGMACS ${ }^{1}$, para a grande São Paulo, mais especificamente sobre as unidades territoriais, o que resultaria em seu primeiro artigo publicado na Revista de Engenharia Municipal: 'A nucleação comercial'. Nele, Flavio apresenta o que "foi provavelmente o primeiro mapa de distribuição territorial das classes sociais da Grande São Paulo" (Villaça, 1988: 8). Surgem daí os elementos analíticos das estruturas urbanas, fruto de estudos de forte caráter empírico que vão se refletir em suas pesquisas acadêmicas, fundamentalmente em seu trabalho de doutorado e, posteriormente, aprimoradas no seu livro 'Espaço Intra-urbano no Brasil', duas décadas mais tarde.

Curiosamente é no período compreendido entre 1960 a 1974, em que suas atividades de pesquisador não estavam ainda circunscritas à universidade, que se encontram as sementes que se desenvolveram em sua tese de doutorado, conforme atestam seu já citado artigo 'A nucleação comercial' de 1960, ou ainda 'A implantação urbana de São Bernardo do Campo' em 1966, resultado de pesquisa em torno do uso do solo. No texto publicado em 1967, em um Suplemento Especial da Folha de São Paulo, intitulado 'Grande São Paulo, Desafio Ano 2000', Villaça inicia a compreensão do espaço metropolitano através dos núcleos urbanos; a localização das atividades; a expansão territorial da indústria e a expansão territorial dos bairros residenciais. Além desse, nos textos 'Metrópole e Desenvolvimento' (Folha de São Paulo 1969); 'Uso do Solo Urbano' e 'A Organização do Espaço na áreas Metropolitanas Brasileiras' (Simpósio sobre Desenvolvimento Urbano e Seminário sobre Shopping Centres, Rio de Janeiro 1973), Villaça parecia buscar descobrir se certos processos territoriais que aconteciam em São Paulo também aconteciam em outras cidades brasileiras.

\footnotetext{
${ }^{1}$ A SAGMACS foi fundada pelo padre dominicano francês Louis- Joseph Lebret que desenvolvera uma teoria- nem comunista, nem capitalista- sobre desenvolvimento regional em países subdesenvolvidos. Essa teoria preconizava a formação de técnicos profissionais tecnicamente aptos e imbuídos da prática de militância para desenvolver planos de desenvolvimento regional. (Angelo,2013:.22). Dentre os técnicos da SAGMACS destacamos: Celso Monteiro Lamparelli, Francisco Whitaker Ferreira, Clementina de Ambrosis, Domingos Theodoro de Azevedo Netto.
} 


\section{SÃO PAULO15 17 LISBOA $25 \sim 26$ JUN 2020

Em 1975, um ano após seu ingresso no corpo docente da FAU USP, inicia seu doutoramento que seria concluído em 1979, com a tese 'A estrutura territorial da metrópole sul brasileira: áreas comerciais e residenciais'. Em suas palavras tal trabalho, que perseguiu a organização espacial das metrópoles brasileiras, "reflete a consciência de que o espaço urbano é produto do trabalho, bem como reflete o papel da luta de classes nessa produção e apropriação do produto" (Villaça, 1988: 29). A continuidade das investigações iniciadas no seu doutoramento e as reflexões dela decorrentes resultaram, em 1988, a publicação daquela que seria sua obra mais referenciada no Brasil, o livro 'Espaço Intra-Urbano no Brasil', considerado um dos mais completos estudos sobre a constituição das metrópoles brasileiras.

Nessa publicação estão claramente expostos os principais núcleos de ideias em que se debruçou para atender seus objetivos, quais sejam, o conceito de espaço intra-urbano, o papel da mobilidade e da acessibilidade no meio urbano, como definidora de centralidades, a disputa pela localização e o conceito de segregação e a forma que assume em nossas metrópoles. Esses temas seriam retomados, em seu último livro publicado em 2012, intitulado 'Reflexões sobre as cidades brasileiras', reverberando os princípios fundamentais que orientam o seu pensamento e obra. Essas obras, assim como, outras tantas de sua autoria vêm instigando novos estudos urbanos e confrontando gerações de pesquisadores e de profissionais a refletir sobre as experiências da gestão sobre as cidades brasileiras.

Sua contribuição aos estudos urbanos e ao planejamento urbano vai muito além do que ensinou sobre a sua história e como não se iludir com seus instrumentos e estratégias, vide o capítulo 'Uma contribuição para a história do planejamento urbano no Brasil' (in DEÁK, SCHIFFER, 1998) ou o livro 'As ilusões do Plano Diretor' (2005) em que analisa a experiência paulistana de elaboração e debates públicos do Plano Diretor Estratégico, durante o governo petista de 2001 a 2004.

Ainda sobre a questão habitacional no Brasil, Villaça expôs suas reflexões e a forma de entender a questão da habitação nos países capitalistas: enquanto uma forma mercadoria que foi se cristalizando com o surgimento do homem livre - produzido pelo próprio capitalismo - e com as configurações históricas engendradas por esse modo de produção, o que resultou em 1986 na publicação ' $O$ que todo cidadão precisa saber sobre habitação', estimulando o debate sobre um tema tão caro à população brasileira.

Com efeito, os trabalhos de Flávio Villaça difundem conceitos ou construções analíticas, sempre sugeridas pela realidade ou prática profissional, atravessando décadas de reflexão, ensaios, estudos e pesquisas antes de vir a público. É o caso de suas reflexões sobre a localização ou a produção da habitação. Sua militância e reflexão crítica constante nos temas que concernem as políticas urbanas contemporâneas, o reconhecimento dessas suas qualidades em outros campos de conhecimento e o conjunto de sua obra escrita, tornou-se inescapável referência para profissionais e interessados nos estudos urbanos, nos motivando e colocando diante do desafio de explorar e identificar, por meio de seus principais escritos, traços e liames da imbricada relação que estabelece entre as teorias do planejamento e a produção socioespacial urbana.

\section{As principais influências e interlocuções no contexto da construção de uma teoria da urbanização na periferia do capitalismo}

Nos anos de seu doutoramento Villaça reconhece que o fenômeno da organização territorial é de natureza complexa e seu entendimento e explicação envolve, necessariamente, às investigações no campo da sociologia, da geografia, da economia e do urbanismo, conforme já sinalizavam as investigações dos teóricos da Ecologia Humana, na Escola de Chicago, do começo do século XX. Neste sentido aponta para o que considera uma das mais importantes obras da economia política, 'Social justice and the city' escrita pelo 


\section{SÃO PAULO15 $\sim 17 \cdot$ LISBOA $25 \sim 26$ JUN 2020

geografo marxista David Harvey e o que considera as mais importantes contribuições para a teoria econômica da distribuição territorial das atividades humanas a nível intra-urbano, quais sejam, 'Toward an understanding of the metropolis' (1926) e 'Regional survey of New York and its environs', interpretações da organização espacial das atividades econômicas no centro de Nova York nos anos 20, escritas pelo economista Robert Muray Haig.

Com efeito, Flávio Villaça realizou seu doutoramento no Departamento de Geografia da Faculdade de Filosofia Letras e Ciências Humanas da USP, culminando, em 1979, com a defesa da tese intitulada 'A estrutura territorial da metrópole sul brasileira: áreas comerciais e residenciais'. Neste percurso as inquietações em encontrar bases teóricas convincentes o levou a frequentar disciplinas de urbanismo, de economia e de sociologia- destacadamente as do arquiteto Professor Celso Lamparelli ${ }^{2}$, em 1975, e as do sociólogo Professor Octávio lanni ${ }^{3}$, em 1977, no curso de Pós-Graduação da Pontifícia Universidade Católica- que foram decisivas à sua adesão ao materialismo histórico e dialético, enquanto postura teórica e suporte de toda a sistematização e explicação da preciosa base empírica que Villaça desenvolveu e que seria fundamental para a publicação, em 1998, do livro 'O Espaço Intra-Urbano no Brasil'.

Também as aulas de Economia Urbana, ministradas pelo prof Juarez Rizzieri ${ }^{4}$, na Faculdade de Economia e Administração da USP (1977), foram substanciais na formulação de analises ao dialogar criticamente com a linha quantitativa e positivista presentes no pensamento do citado professor e do investigador em economia espacial, o argentino-americano William Alonso, então conhecido por seus estudos sobre renda da terra e a organização intra-urbana.

Alonso foi o primeiro economista urbano a investigar a localização intra-urbano da residência à luz da teoria econômica, presente em sua publicação 'The Historical and the structural theories of urban form: their implications for urban renewal', onde apresenta sua teoria estrutural e um resumo de sua teoria sobre localização residencial. O diálogo crítico de Villaça com as obras de Alonso encontra-se espelhado no artigo 'A teoria de Alonso e a Cidade Brasileira' (VILLAÇA, 1988), em que questiona a tese deste estudioso argentino, sobre a localização dos pobres e dos ricos nas cidades americanas e mostra quão distante e inaplicável estava aquela teoria, para realidade brasileira.

No campo de conhecimento da Sociologia, Villaça reconhece a relevante contribuição dada por esta disciplina à localização da residência nos estudos espaciais intra-urbano, em especial, pela repercussão e a divulgação dos estudos dos ecologistas da Escola de Chicago, destacadamente, Ernest Burgess, Robert Park e Roderic McKenzie. Villaça entende os estudos da Escola de Chicago de observação e levantamento dos fenômenos, os esforços de classificação e verificação de suas regularidades, bem como o quanto dessas tarefas eram incorporadas sinteticamente nos modelos por eles desenvolvidos: uma síntese que representava um grande avanço em direção à interpretação da localização das residências no espaço urbano.

\footnotetext{
${ }^{2}$ Integrante da equipe de São Paulo da Sociedade para Análise Gráfica e Mecanográfica Aplicada aos Complexos Sociais-SAGMACS, Celso Lamparelli já havia tomado contato com o pensamento do padre Lebret antes mesmo de nela ingressar, em especial sobre a importância das categorias da economia marxista em seus estudos (Angelo,2013: 72)

${ }^{3}$ Octávio lanni, integrou juntamente como Florestan Fernandes, Roger Bastide, a Escola de Sociologia Paulista, formada na década de 1940, voltada aos estudos das relações raciais no Brasil.

${ }^{4}$ Juarez Alexandre Baldini Rizzieri é economista, professor doutor da FEA -USP. No período em que Flavio frequentou suas aulas, o professor havia feito mestrado na Purdue University, dos Estados Unidos (1969), já ministrava aulas na USP de Introdução à Economia, Macro e Micro-economia e Economia Monetária Moedas e Bancos. Em 1968 publicou o livro Função Consumo no Brasil 1948/1960 e 1948/1964.
} 


\section{SÃO PAULO15 $\sim 17 \cdot$ LISBOA $25 \sim 26$ JUN 2020

Em sua crítica ao trabalho desses ecologistas Villaça se aproxima de Castells ao afirmar que os ecologistas estavam mais preocupados em constatar do que explicar suas causas, mesmo reconhecendo a importância do conteúdo descritivo daqueles trabalhos. Naqueles anos, Castells havia desenvolvido sua teoria espacial intra-urbana e apresentada no capítulo 'Le débat sur la théorie de l'espace', de seu livro 'La questión urbaine' (1972), considerada por Flávio Villaça, bastante abrangente.

Um dos principais desdobramentos da aproximação de Villaça com o trabalho de Castells, foi o de se conscientizar que seu trabalho de doutoramento estava incorrendo nos mesmos problemas que o sociólogo catalão havia criticado no modelo de Burgess, ou seja, o de buscar inutilmente a regularidade pela regularidade, ao não contar com uma investigação das verdadeiras causas dos fenômenos espaciais e por relevar a importância da determinação das 'condições de base'. O trabalho de Castells integrava uma linha teórica surgida nas décadas de 1960 e 1970, conhecida como 'Escola francesa de sociologia marxista' que pretendia interpretar a estrutura intra-urbana a partir de processos sociais: uma forma de interpretar que tinha, na visão de Flávio Villaça, validade universal por se aplicar a diferentes culturas e períodos históricos. Esse grupo iria disseminar entre os analistas das cidades a "premissa de que o Estado e a política seriam epifenômenos de processos produzidos por atores e processos situados na sociedade" (MARQUES, 2016: 6), ou seja, que para entender as cidades, bastava observar os efeitos dos processos societais, sobre as instituições políticas.

O sociólogo Manuel Castells e o geógrafo David Harvey e os também fundamentais nomes na literatura de estudos dos espaços urbanos, Henri Lefebvre e Jean Lojikne, dentre outros, constituíam um corpo teórico fortemente impactado por interpretações do marxismo, as quais Villaça viria adotar, em especial, a concepção geral, de que as estruturas territoriais e não territoriais, como a econômica, a política e a ideológica estão interacionadas,

No período em que Flavio Villaça, então como professor da Faculdade de Arquitetura e Urbanismo da Universidade São Paulo/FAU-USP, operava seu doutoramento e se aproximava aos trabalhos do sociólogo Manuel Castells, (então professor da Universidade de Paris e coordenador do Centro Interdisciplinar de Desenvolvimento Urbano e Regional de Santiago do Chile), outros dois grupos de intelectuais marxistas brasileiros, que também dele se aproximariam influenciados pelo estruturalismo francês iriam contribuir com o debate em direção ao que poderia vir a ser uma teoria da urbanização na periferia do capitalismo (Arantes, 2009; Marques, 2016). Um desses grupos de intelectuais estava reunido em torno do Centro Brasileiro de Análise e Planejamento - CEBRAP e o outro, em torno da Faculdade de Arquitetura e Urbanismo da Universidade São Paulo/FAU-USP.

Dentre os pesquisadores do CEBRAP destacavam-se o economista Paul Singer, os sociólogos Francisco de Oliveira, Fernando Henrique Cardoso, Lúcio Kowarick e Cândido Ferreira de Camargo, além do geógrafo Milton Santos. Um dos mais significativos desses diagnósticos produzidos pelo CEBRAP foi publicado em 1976, sob o título 'São Paulo, 1975: crescimento e pobreza', iniciativa compartilhada pela Comissão Justiça e Paz da Arquidiocese de São Paulo.

Dos professores da FAU-USP, destacavam-se Ermínia Maricato, Gabriel Bolaffi, Rodrigo Lefebvre e Paul Singer, e os jovens pesquisadores Raquel Rolnik e Nabil Bonduki, que editariam com textos de 1975 a 1979 o livro 'A produção da casa (e da cidade) no Brasil industrial', considerado uma marcante contribuição para o entendimento do fenômeno urbano nos anos 1970. Para Pedro Arantes (2009), a proximidade de temas e certa filiação com o Cebrap são evidentes, inclusive pela participação de Paul Singer, com um artigo, e de 


\section{SÃO PAULO15 $\sim 17 \cdot$ LISBOA $25 \sim 26$ JUN 2020

Francisco de Oliveira, no prefácio. Segundo Arantes, a escolha dos dois não é casual, pois a 'Crítica à razão dualista' (Oliveira, 1972) e 'A economia política da urbanização' (Singer, 1973) eram dos textos mais lidos e debatidos naqueles anos entre os arquitetos de esquerda, como primeiras interpretações marxistas do urbano no Brasil.

Em ambos os grupos e no trabalho de doutorado do Villaça a contribuição das analises para se entender as cidades se concentravam, nas palavras de Marques (2016, p.19), na produção de espaço urbano e em dimensões econômicas, o que para ele era plenamente justificada dada a pequena importância relativa da política local naquela época.

\section{Considerações finais}

A contribuição de Flávio Villaça a reflexão e prática no campo do planejamento e dos estudos sobre espaço urbano, pode ser avaliada por diferentes enfoques, desde a identificação de seus interlocutores teóricos até a original formulação de conceitos e aplicações metodológicas. Em cada uma dessas abordagens é possível captar sua persistência e compromisso em não apenas buscar a verdade, mas "...diferenciar e selecionar as verdades" (VILLAÇA, 2012: 281), como ele define ser o maior desafio do cientista social.

Outra característica deste profissional do planejamento, pesquisador e professor, além de sua disposição ao diálogo, é a inquietação intelectual manifestada desde a sua formação em Arquitetura e Urbanismo, quando já cruzava fronteiras dos campos de conhecimento, percorrendo as vizinhanças da FAU - USP para frequentar as aulas de 'Introdução a Sociologia', ministradas por quem ele considera até hoje o "[...] melhor professor que tive na vida" (VILLAÇA, 2012: 276) - Antônio Cândido de Mello e Souza.

Aliada a essa qualidade, deve ser destacada sua honestidade e coragem intelectual, quando admite humildemente:

"[...] quando eu escrevia minha tese de doutorado, ficava apreensivo ao escrever a expressão 'classe social'. Evitei quanto pude usar essa expressão. Eu acreditava que se a usasse, iriam inevitavelmente me arguir sobre qual era o meu conceito de 'classe social'. Não poderia nem pensar em responder perguntas sobre ele. Por isso, em vez de 'classe' usei - talvez equivocadamente, mas ninguém nunca me questionou sobre isso - a palavra 'camada'; cunhei assim a expressão 'camadas de alta renda', que aliás mantive ('região de alta concentração das camadas de alta renda') no meu livro "Espaço intra-urbano no Brasil [...]" (VILLAÇA, 2012: 276)

Mas para além dessas nuances de personalidade, está sempre presente nas obras, publicações, atividades acadêmicas de Villaça seu compromisso com o rigor científico, necessário para compreender seu principal objeto de estudo - o espaço urbano, para o qual concorrem as contribuições de várias disciplinas, e sua responsabilidade ética para "[...] espacializar os processos sociais" - papel essencial desse 'cientista social' de múltiplas formações. Pois, mesmo sendo a geografia, o campo primordial da teoria e análise da estrutura social e espacial, Villaça ainda considera essencial a interlocução com "[...] todos os pensadores que se dedicam a investigação dos mais variados aspectos da sociedade [...]" incluindo nesse rol os "[...] economistas, cientistas políticos, planejadores urbanos, historiadores, geógrafos humanos, sociólogos, publicitários, advogados, antropólogos, etc." (idem, p. 286). Uma vez que para ele, "[...] entender o espaço é

\footnotetext{
${ }^{5}$ A primeira publicação dessa obra de Francisco de Oliveira ocorreu em 1972, como um ensaio, no número 2 de Estudos Cebrap, com o título "A economia brasileira: crítica à razão dualista". Posteriormente foi editado como livro (1973) e reeditado em 2003.
} 


\section{SÃO PAULO15 17 LISBOA $25 \sim 26$ JUN 2020}

entender como ele participa das transformações sociais. Não existe transformação social sem a participação do espaço, e não existe a transformação do espaço sem a transformação social ". (VILLAÇA, 2012: 287).

Desde quando foi instigado pelos debates sobre a natureza da 'Questão Urbana' (Castells) nos anos 1970, os estudos urbanos vêm recebendo reforços de diversos campos das ciências sociais, especialmente nas últimas décadas. Na trajetória de Flávio Villaça não tem sido diferente. Pode-se reconhecer naquele primeiro momento de crítica radical aos estudos urbanos a coincidência com um período de especial interlocução intelectual, como ele mesmo aponta, ao se filiar àqueles autores que propagam a ideia de espaço social ser socialmente produzido - Lefebvre, Harvey, entre outros (VILLAÇA, 2012: 289).

Hoje, apesar do alerta de Brenner e Schmid (2015) de que o contexto de reestruturação urbana prenuncia uma crise estrutural de longo alcance para os estudos urbanos, quando nos voltamos aos estudos urbanos especialmente voltados para a realidade das cidades brasileiras, esta ameaça parece ainda distante. Pois podemos verificar uma expressiva produção de estudos e pesquisas sobre o espaço urbano que combina e compartilha, a partir de diferentes campos do conhecimento, não sem alguns conflitos, os fundamentos teóricos, que já estruturavam as inquietações presentes ao longo da trajetória intelectual de Flávio Villaça.

Pelo menos é o que se pode depreender nas inúmeras citações e referências a suas obras encontradas em artigos publicados em periódicos das áreas da demografia, antropologia, saúde pública, ecologia urbana, ou da engenharia sanitária e de transportes, além é claro, das produções nos campos da geografia, arquitetura e urbanismo. Numa pesquisa exploratória sobre referências bibliográficas na base Google Acadêmico, foram registradas cerca de 2.000 citações e referências a obra 'O Espaço intra-urbano no Brasil' de Flávio Villaça, desde sua publicação, em 1998. As metodologias hoje disponíveis para identificação, análise e sistematização de produção bibliográfica e científica proporcionada pelas bases de dados de citações e resumo de literatura - revistas científicas, livros e conferências - hoje acessíveis no meio acadêmico, permite mapear as redes de disseminação das ideias e a abrangência dos conhecimentos ensinados.

Sugerindo uma investigação em sentido contrário - não mais sobre quais aportes teóricos compõem o campo do planejamento urbano, mas sobre como o urbano ou a urbanização, enquanto categorias teóricas, aportam os demais campos das ciências sociais -, é possível identificar na produção de Flávio Villaça, como suas contribuições estão sendo apropriadas por estudos urbanos de diversas filiações científicas, e como sua trajetória intelectual instigante pode estar animando diálogos e ensinando a entender o espaço urbano em suas múltiplas dimensões e articulações com o social. Este poderá ser um próximo desafio de etapa de pesquisa.

\section{Referências Bibliograficas}

ANGELO, M. R. (2013) Louis-Joseph Lebret e a SAGMACS: a formação de um grupo de ação para o planejamento urbano no Brasil. São Paulo: Alameda.

ARANTES, P. F. Em busca do urbano: marxistas e a cidade de São Paulo nos anos de 1970. Novos estudos - CEBRAP [online]. 2009, n. 83, 103-127.

BRENNER, N., SCMID, C. (2015) Toward a new epistemology of the urban? City, vol19, n.2-3, 151-182.

CAMARGO, C. P. F. et al (1975) São Paulo 1975 Crescimento e pobreza. São Paulo: Ed. Loyola.

MARICATO, E. (org.) (1982) A produção da casa (e da cidade) no Brasil industrial. São Paulo: Alfa-Ômega. 


\section{XII}

MARQUES, E. C. L. (2016) Notas sobre a política e as políticas do urbano no Brasil. São Paulo: Centro de Estudos da Metrópole, 2016.

VILLAÇA, F. J.M. (2012) Reflexões sobre as cidades brasileiras. São Paulo: Studio Nobel.

(1988) Sistematização crítica da obra escrita pelo professor Dr. Flávio José Magalhães Villaça sobre espaço urbano. Texto submetido a concurso público para obtenção de título de livre-docente junto à disciplina AUP-260, Planejamento Urbano II. São Paulo: FAU USP. 